\title{
Study of Effect of Variations in slot dimensions on Fractal Patch antenna Performance
}

\author{
Ms. Monika, Mr. Somesh Kumar \\ Assistant Professor, Panjab University (PUSSGRC), Chandigarh \\ er.monika.shukla@gmail.com \\ Assistant Professor, Panjab University (PUSSGRC), Chandigarh \\ somesh.dahiya@gmail.com
}

\section{ABSTRACT}

An antenna is a device that is made to efficiently radiate and receive radiated Electromagnetic waves. Microstrip antennas are attractive due to their light weight, conformability and low cost. These antennas can be integrated with printed strip-line feed networks and active devices. This is a relatively new area of antenna engineering. For reducing the size of antenna, fractal geometries have been introduced in the design of patch antenna. Fractal antennas also called as space filling curves are very compact, multiband or wideband, and have useful applications in cellular telephone and microwave communications. In our research work, we have used IE3D software for designing the antenna. We study the effect of variations of slot dimensions on antenna performance so as to obtain good results. In this research work, four different fractal patch antennas are designed. The rectangular base geometry is same for the all four antennas but the elliptical slot dimensions differ. In simulation, $\mathbf{S}$ parameters of all four antennas are analyzed. From the $\mathbf{S}$ parameter displays, comparison of all four antennas is done on the basis of three parameters that are: Lowest frequency, Multiband and $S_{11}$ values. The simulation results shows that as the elliptical slot dimension decreases on rectangular patch antenna, the performance of fractal patch antenna improves on the basis of three factors that are lowest frequency, multiband and $\mathrm{s}_{11}$ values.

\section{KEYWORDS}

Microstrip antenna, Fractal antenna, S parameters, Lowest frequency, Multiband and $\mathrm{S}_{11}$ values.

\section{INTRODUCTION}

An antenna is a device that is made to efficiently radiate and receive radiated Electromagnetic waves. Wireless communication plays a great role in our daily existence, with antennas being of continuously increasing significance. Microstrip patch antenna is becoming most popular in wireless communication applications. Microstrip patch antennas have various advantages such as low profile, light weight, easy fabrication and conformability to mounting hosts in addition size reduction and bandwidth enhancement are major design considerations for practical applications of microstrip antennas [1].

However, the size of a conventional microstrip antenna is typically large when designed in microwave frequency regime causing problems for mounting on transmitter/receiver and repeater systems. These antenna types also have limitations in terms of their narrow bandwidth, low gain, and weak radiating patterns. The gain reduction is caused by the overall reduction in the antenna size. It can also be attributed to the substrate characteristics which may lead to surface wave excitation and hence a reduction in gain. Therefore, it is challenging to design microstrip antennas to have better radiating properties and in the same time have a smaller size [2]. These antennas can be integrated with printed strip-line feed networks and active devices. A very important contributing factor for recent advances of microstrip antennas is the current revolution in electronic circuit miniaturization brought about by developments in large scale integration. The size of MPA is basically determined by its resonance length and width [3]. A microstrip antenna is characterized by its Length, Width, Input impedance, and Gain and radiation patterns. A microstrip antenna consists of conducting patch on a ground plane separated by dielectric substrate as shown in Figure 1.

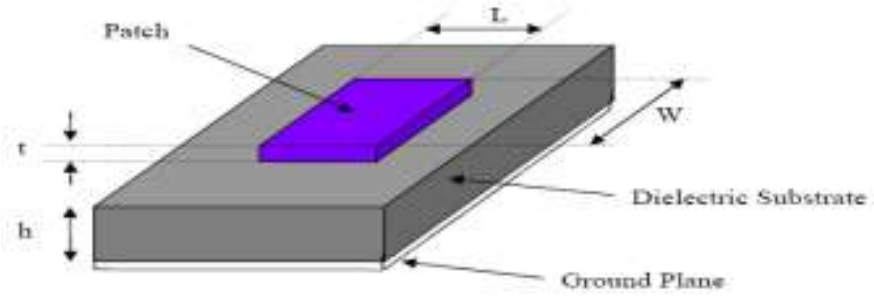

Fig 1: Structure of a Microstrip Patch Antenna.

Microstrip patch antennas can be fed by a variety of methods. The four most popular feed techniques used are the microstrip line, coaxial probe (both contacting schemes), aperture coupling and proximity coupling (both non-contacting schemes). For reducing the size of antenna, fractal geometries have been introduced in the design of patch antenna. A fractal is "a rough or fragmented geometric shape" that is generated by starting with a very simple pattern that grows through the application of rules. Fractal geometries have two common properties: Self-similar property, Space filling property. The self-similarity property of certain fractals results in a multiband behavior. Using the self-similarity properties a fractal antenna can be designed to receive and transmit over a wide range of frequencies. While using space filling 
properties, a fractal make reduce antenna size [4].The existence of infinite fractal geometries and their advantages opens the door to endless possibilities to accomplish the task at hand. The use of fractals provides us with a bigger set of parameters to control the antenna characteristics [5]. Figure 2 shows the properties of fractals.

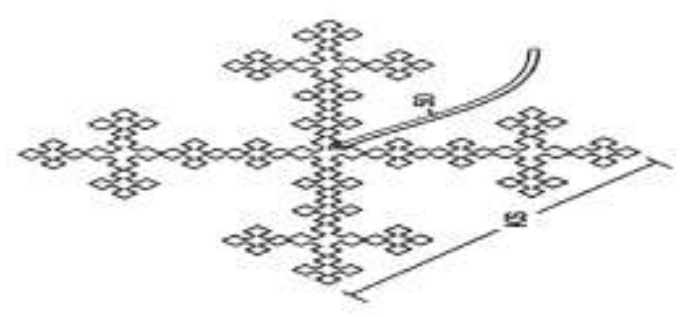

Fig 2: Space filling curve with self similar design.

A fractal antenna's response differs markedly from traditional antenna designs, in that it is capable of operating with goodto-excellent performance at many different frequencies simultaneously. Generally standard antennas have to be "cut" for the frequency for which they are to be used and thus the standard antennas only can work well at that frequency. This makes the fractal antenna an excellent design for wideband and multiband applications. The key features of fractal antenna technology are reduced antenna size, Multi-band functionality, improved antenna performance etc. Robust communications links are achieved with fractal-shaped antennas by not only using repeating and self-similar shapes, but also with irregular shapes that may not be immediately recognised as fractal. To perform Simulation of Fractal patch Antenna different software's are available [6].

IE3D is used in this work because of its multi-threaded and distributed simulation architecture and high design capacity. In this paper we study the effect of variations of slot dimensions on fractal patch antenna performance so as to obtain good results. In this paper further four different fractal patch antennas are designed [7]. The rectangular base geometry is same for the all four antennas but the elliptical slot dimensions differ. In simulation, $\mathrm{S}$ parameters of all four antennas are analyzed. The $S$ parameter graph shows the relationship between return loss $\left(S_{11}\right)$ and frequency. From the $S$ parameter displays, comparison of all four antennas is done on the basis of three parameters that are:

1. Lowest frequency

2. Multiband

3. $\mathrm{S}_{11}$ values

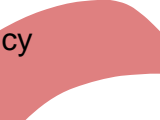

In the next sections the Fractal Antenna Design Procedure, Design Parameters, simulation results and conclusions based on the simulations are explained.

\section{FRACTAL ANTENNA DESIGN}

In this section, the procedure for designing a Fractal Patch Antenna in IE3D software is explained. The design parameters are also explained in this section.

\section{Design Parameters}

The following specifications are taken into account for the design of Fractal Patch Antenna:

1. Practical Length $(\mathrm{L})=40.3 \mathrm{~mm}$.

2. Practical width $(w)=49.4 \mathrm{~mm}$.

3. Frequency $\left(\mathrm{f}_{\mathrm{r}}\right)=2.4 \mathrm{GHz}$.

4. Height $(\mathrm{h})=3.175 \mathrm{~mm}$.

5. Velocity of light $(\mathrm{c})=3 \times 10^{8} \mathrm{~m} / \mathrm{s}=3 \times 10^{11} \mathrm{~mm} / \mathrm{s}$.

6. Dielectric constant $\left(\varepsilon_{\mathrm{r}}\right)=2.2$

7. Loss Tangent $(\tan \delta)=0.0009$

8. Radius of co-axial cable $=0.5 \mathrm{~mm}$.

Feed point is located where input impedance is matched to 50 ohms and where return loss is most negative. Low dielectric constant substrates are generally preferred for maximum radiation. The conducting patch can take any shape but rectangular and circular configurations are the most commonly used configuration.

In this work, four different fractal patch antennas are designed. The rectangular base geometry is same for the all four antennas but the elliptical slot dimensions differ.

The rectangular base geometry dimensions are:

1. Practical Length $(L)$ of rectangle $=40.3 \mathrm{~mm}$.

2. Practical width $(\mathrm{w})$ of rectangle $=49.4 \mathrm{~mm}$. 
The elliptical slot dimensions for the antenna are shown in Table 1. The various antenna design based on elliptical slot dimension is given in Figure $3 a, 3 b, 3 c, 3 d$.

Table 1. Fractal patch Antenna elliptical slot dimensions

\begin{tabular}{|c|c|c|c|c|}
\hline $\begin{array}{c}\text { Elliptical slot } \\
\text { dimensions }\end{array}$ & Antenna 1 & Antenna 2 & Antenna 3 & Antenna 4 \\
\hline Primary axis(mm) & 20 & 16 & 10 & 5 \\
\hline Secondary axis(mm) & 24.5 & 22.62 & 16 & 8 \\
\hline
\end{tabular}

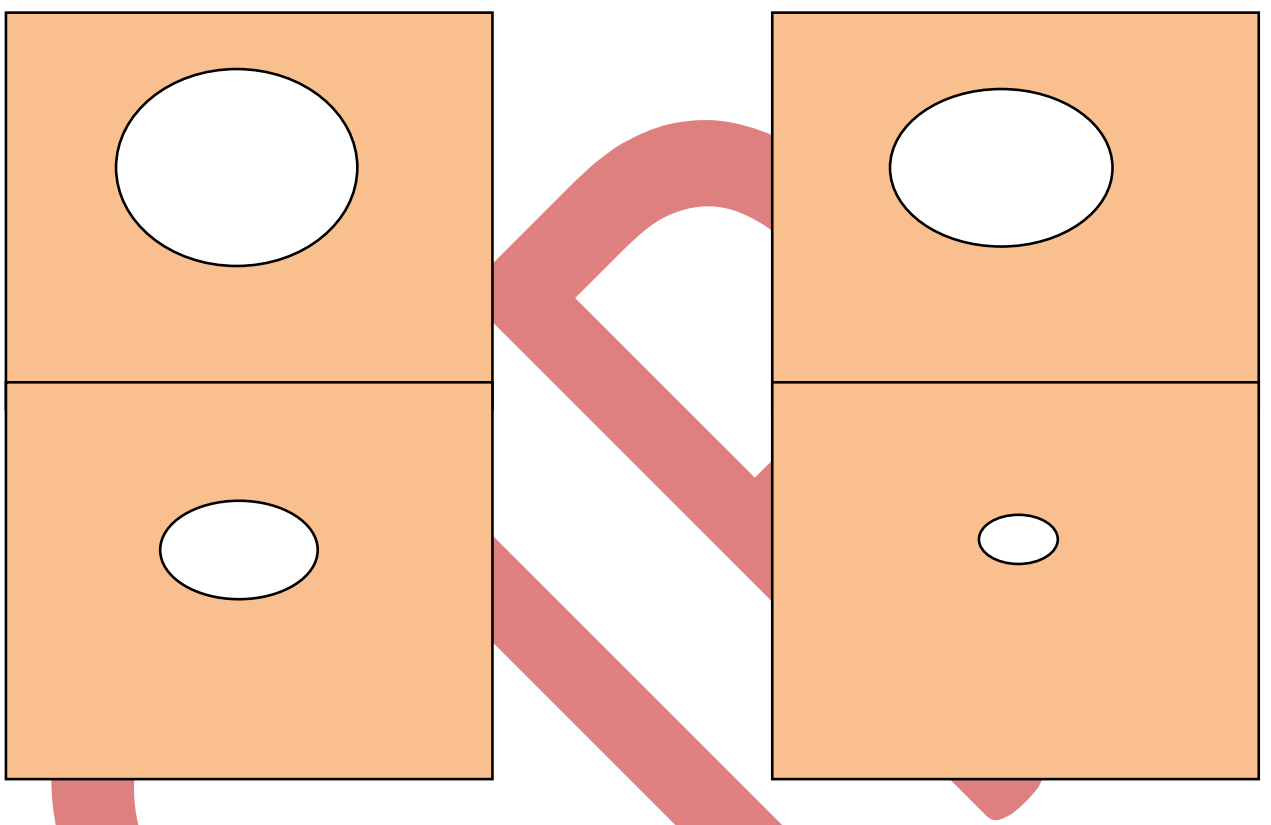

\section{SIMULATION AND RESULTS}

In simulation, $\mathrm{S}$ parameters of all four antennas are analyzed [8-10]. From the S parameter displays, comparison of all four antennas is done on the basis of three parameters that are:

1. Lowest frequency

2. Multiband

3. $\mathrm{S}_{11}$ values

Lowest frequency: The lowest frequency means the minimum operating frequency of an antenna on which antenna can work satisfactory. Under this, we observe the minimum operating frequency of all the four designed antennas from the $S$ parameter displays [11]. The S parameter of all four designed antennas showing the lowest frequency of all the designed antennas are shown in Figure 4, 5, 6, 7 as follows [12]. Figure 4 shows the $S$ parameter display of antenna 1 for the observation of lowest frequency operation.

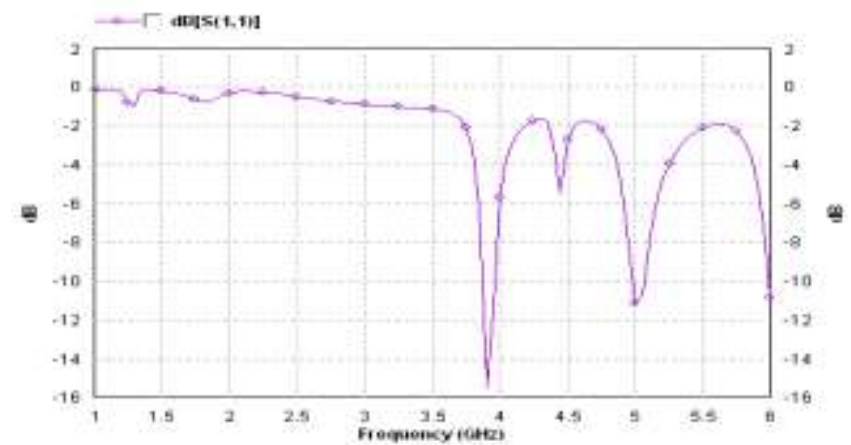

Fig 4: S parameter display of antenna 1 showing lowest frequency.

Figure 5 shows the $\mathrm{S}$ parameter display of antenna 2 for the observation of lowest frequency operation. 


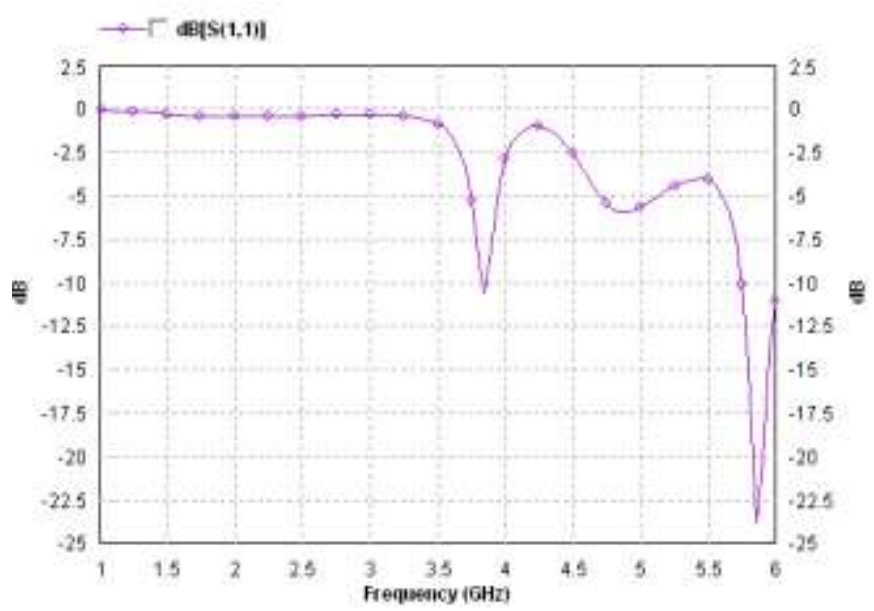

Fig 5: S parameter display of antenna 2 showing lowest frequency.

Figure 6 shows the $S$ parameter display of antenna 3 for the observation of lowest frequency operation.

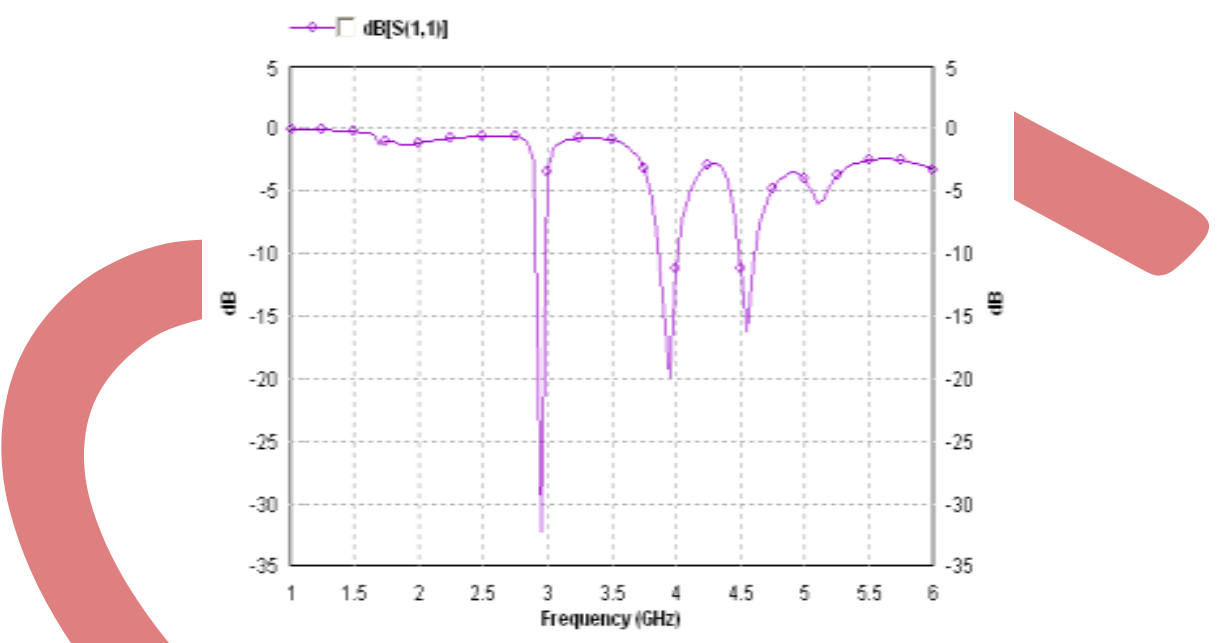

Fig 6: S parameter display of antenna 3 showing lowest frequency.

Figure 7 shows the $S$ parameter display of antenna 4 for the observation of lowest frequency operation.

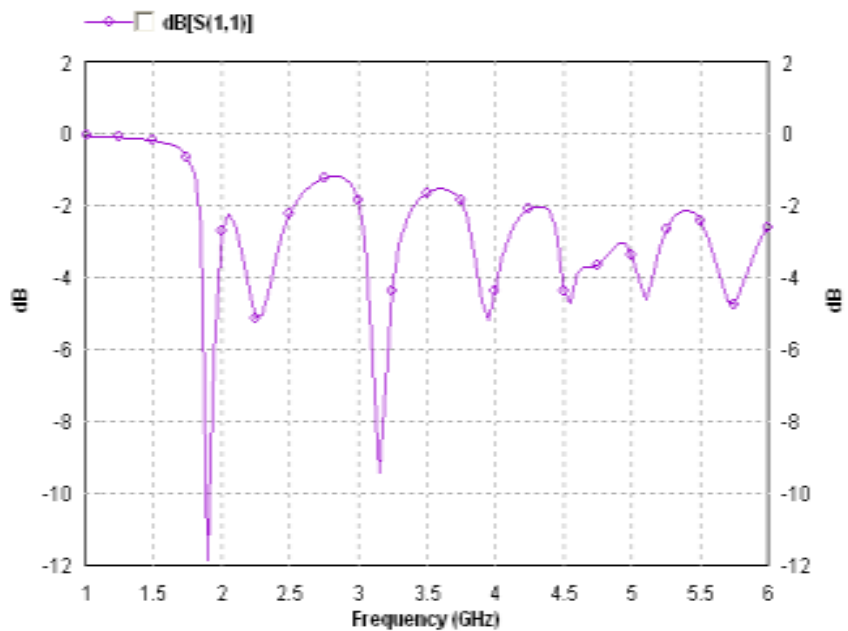

Fig 7: S parameter display of antenna 4 showing lowest frequency.

From the above $S$ parameter displays of the four designed antennas,it is clear that with the reduction in elliptical slot dimensions the lowest frequency of operation on which antenna can work satisfactory, decreases. 
Council for Innovative Research www.cirworld.com
International Journal of Computers \& Technology

Volume 5, No. 1, May -June, 2013, ISSN 2277-3061

Multiband: Under this, the multiband operation is observed from $\mathrm{S}$ parameters displays for all four designed antennas. The S parameter display showing the number of frequencies on which antenna can operate satisfactory is shown in Figure $8,9,10,11$ as follows.

Figure 8 shows the S parameter display of antenna 1 for the observation of multiband frequency operation.

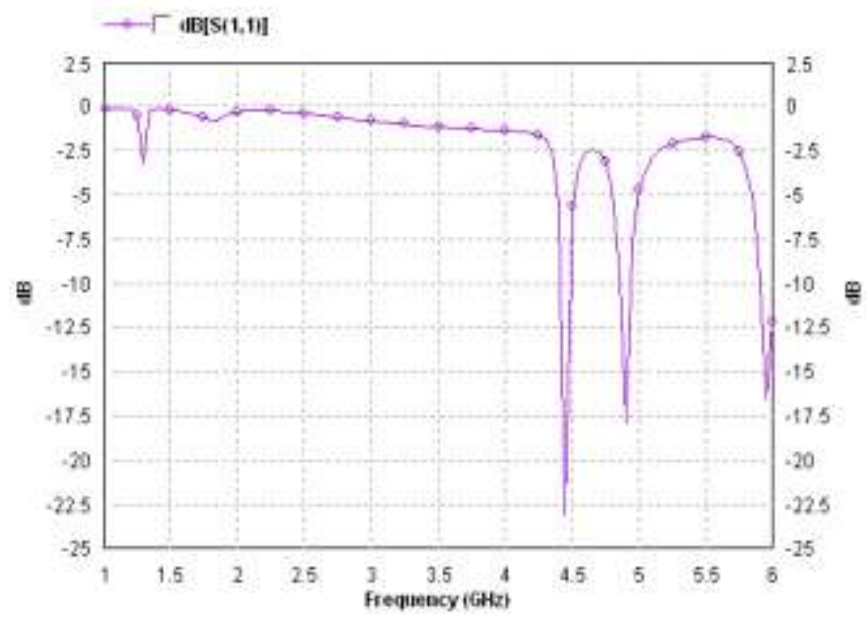

Fig 8: S parameter display of antenna 1 showing multiband frequency operation.

Figure 9 shows the $S$ parameter display of antenna 2 for the observation of multiband frequency operation.
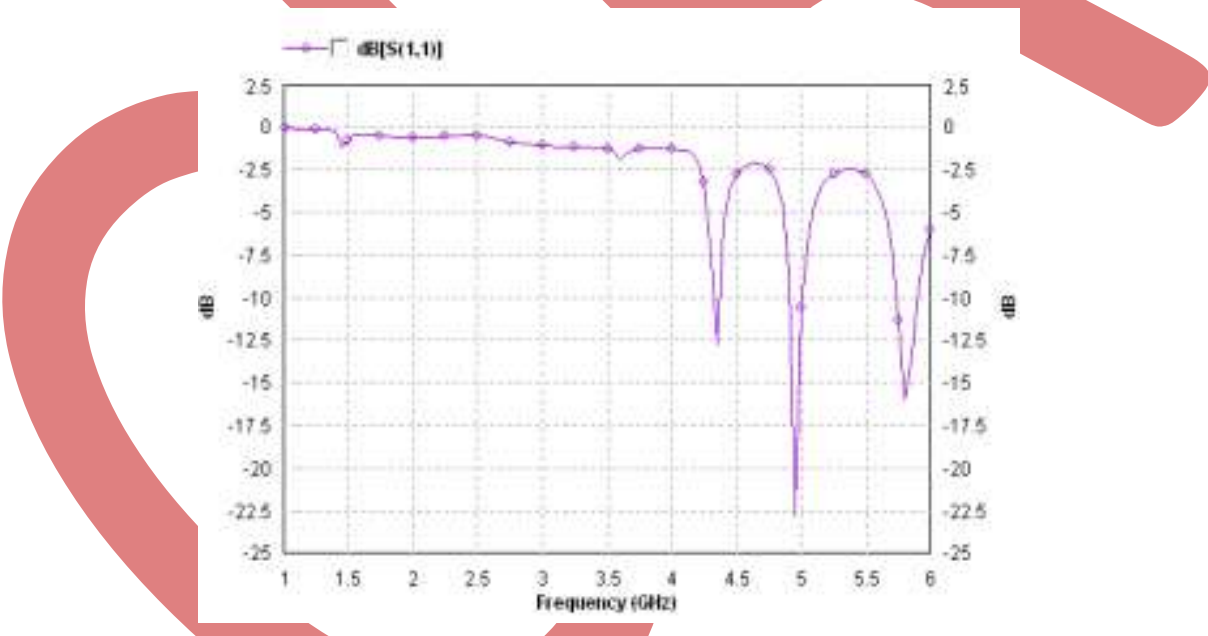

Fig 9: S parameter display of antenna 2 showing multiband frequency operation.

Figure 10 shows the $S$ parameter display of antenna 3 for the observation of multiband frequency operation.

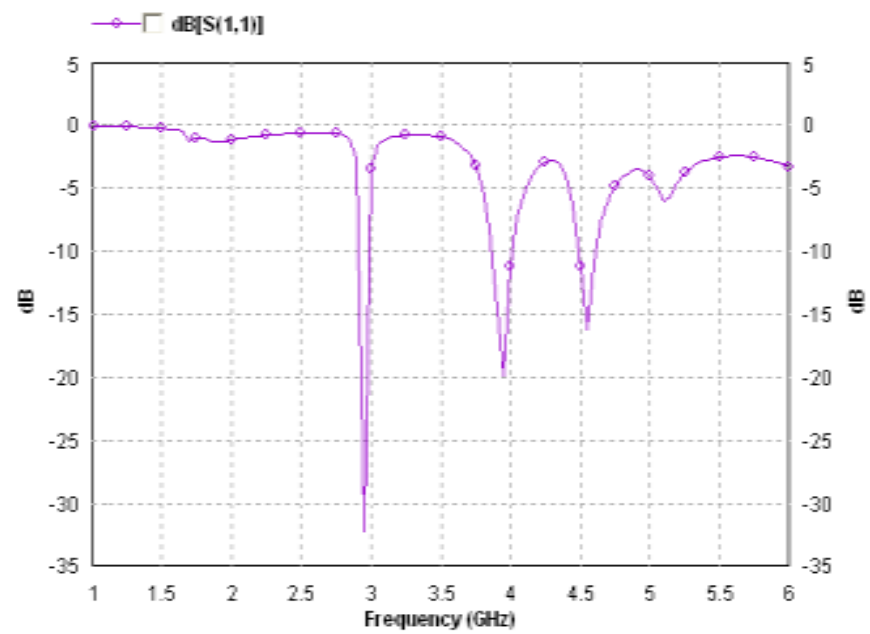


Fig 10: S parameter display of antenna 3 showing multiband frequency operation.

Figure 11 shows the $S$ parameter display of antenna 4 for the observation of multiband frequency operation.

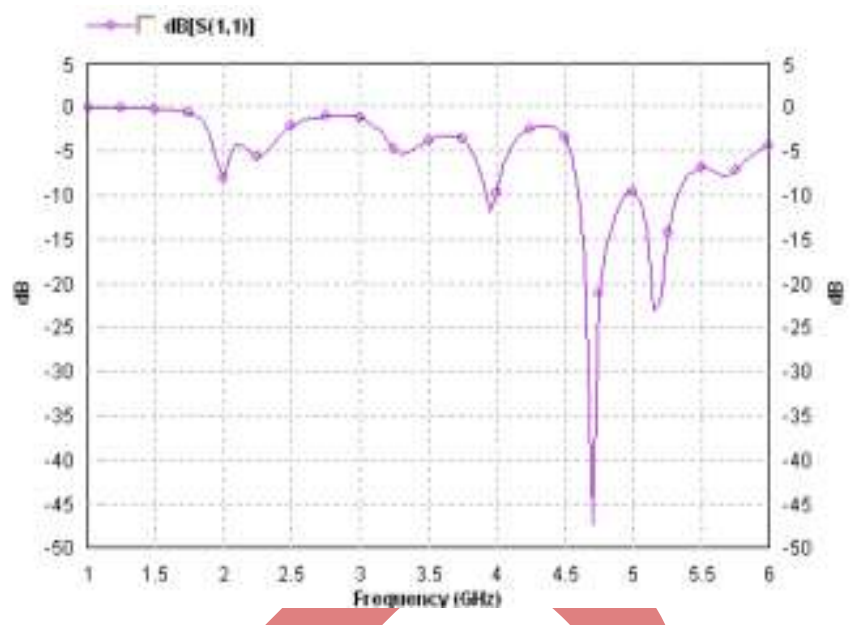

Fig 11: S parameter display of antenna 4 showing multiband frequency operation.

From the above $S$ parameter displays of the four designed antennas,it is clear that with the reduction in elliptical slot dimensions there is not much effect on multiband frequency operation.

$S_{11}$ value: It is also called return loss. It is defined as the ratio of the reflected back power to the incident power. For good antenna its value should be more negative then $-10 \mathrm{~dB}$.Under this from the $\mathrm{S}$ parameter displays of all the four designed antennas minimum return loss for all the four antennas is observed and shown in Figure 12, 13, 14, and 15 as follows.

Figure 12 shows the $S$ parameter display of antenna 1 for the observation of $S_{11}$ value.

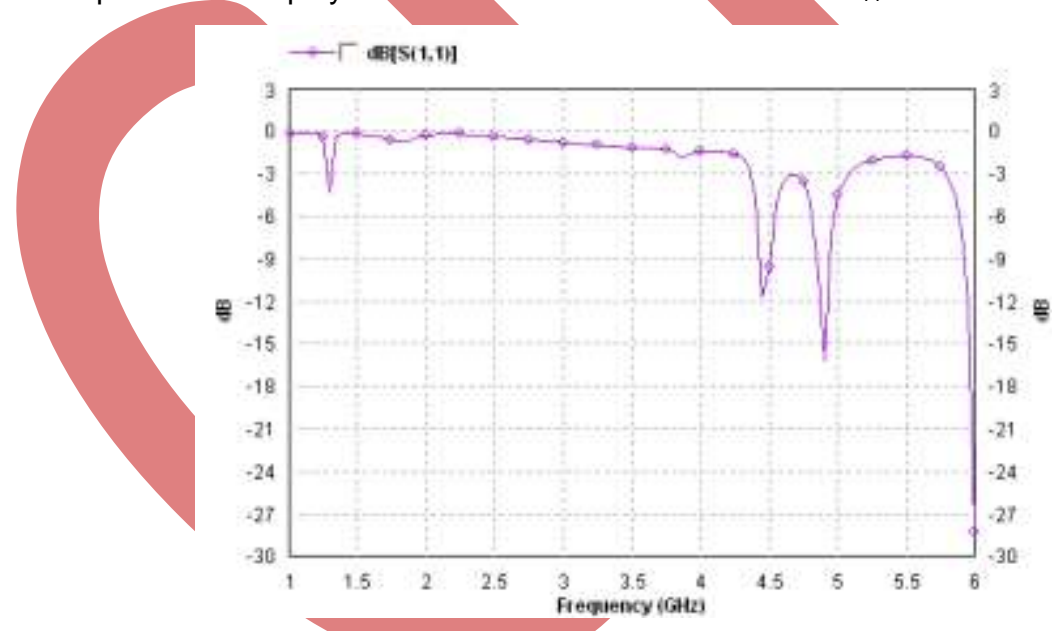

Fig 12: $S$ parameter display of antenna 1 showing the $S_{11}$ value.

Figure 13 shows the $S$ parameter display of antenna 2 for the observation of $S_{11}$ value.

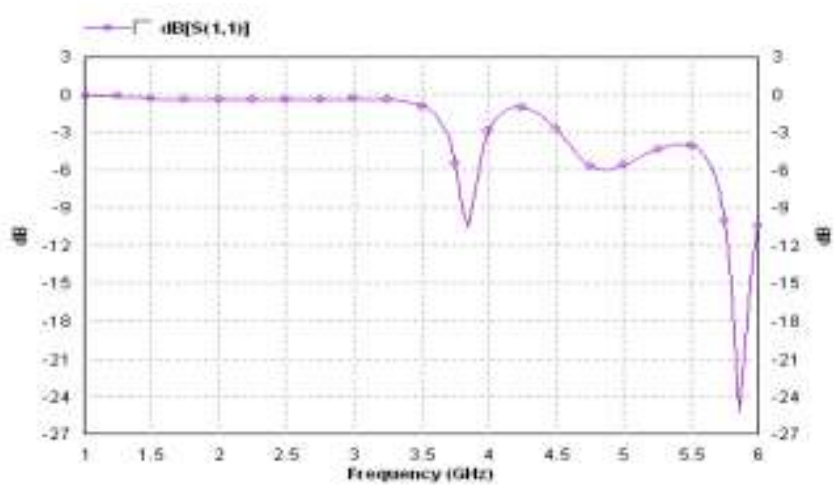

Fig 13: $S$ parameter display of antenna 2 showing the $S_{11}$ value. 
Figure 14 shows the $\mathrm{S}$ parameter display of antenna 3 for the observation of $\mathrm{S}_{11}$ value.

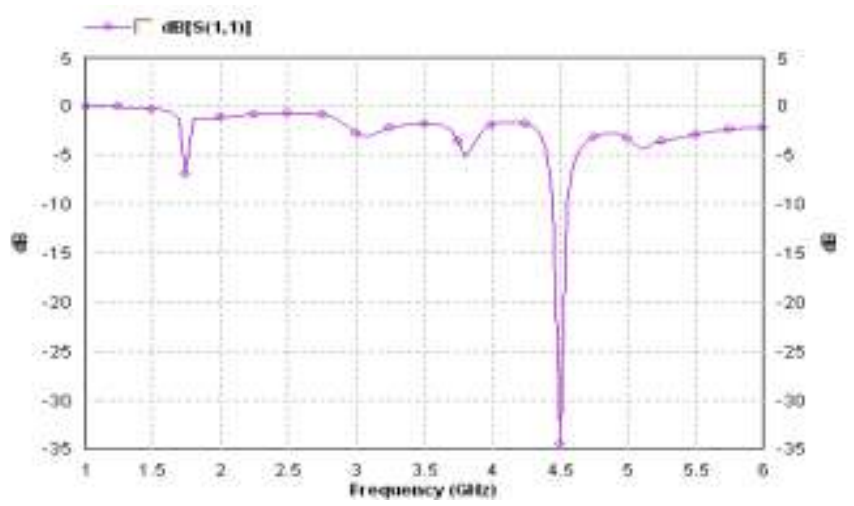

Fig 14: $S$ parameter display of antenna 3 showing the $S_{11}$ value.

Figure 15 shows the $S$ parameter display of antenna 4 for the observation of $S_{11}$ value.

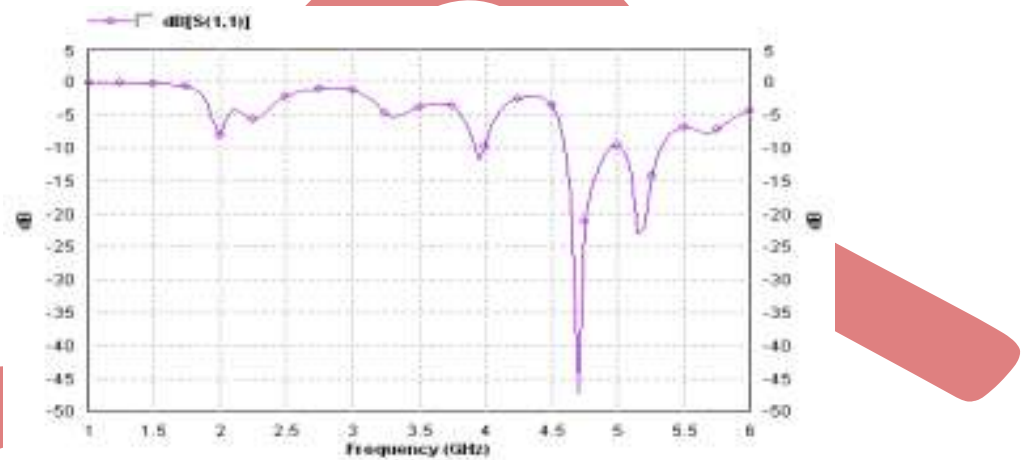

Fig 15: $S$ parameter display of antenna 4 showing the $S_{11}$ value.

From the above $\mathrm{S}$ parameter displays of the four designed antennas,it is clear that with the reduction in elliptical slot dimensions the $S_{11}$ value also reduces. The lowest frequency, Multiband and $S_{11}$ values of all the four fractal patch antennas are shown in Table 2.

Table 2: Comparison of antennas on the basis of lowest frequency, multiband and $\mathbf{S}_{11}$ values.

\begin{tabular}{|c|c|c|c|c|}
\hline $\begin{array}{c}\text { S parameter } \\
\begin{array}{c}\text { Lowest frequency } \\
\text { (GHz) }\end{array}\end{array}$ & Antenna 1 & Antenna 2 & Antenna 3 & Antenna 4 \\
\hline Multiband & 3.839 & 2.948 & 1.892 \\
$(\mathrm{GHz})$ & 4.4507 & 4.3450 & 2.9483 & 4.4507 \\
& 5.8967 & 4.9436 & 3.9460 & 4.8964 \\
& 5.9530 & 5.8004 & 4.5446 & 5.9882 \\
\hline $\mathbf{S}_{11}$ values & -24.506 & -24.701 & -33.348 & -45.651 \\
\hline
\end{tabular}

The all four fractal patch antennas are compared in the above Table 2. The four designed antennas have been analyzed from the $S$ parameter displays. The performance of the four designed antennas is observed on the basis of three parameters that are lowest frequency, multiband operation and $S_{11}$ values. It is clear from the table that with reduction in the elliptical slot dimensions on the rectangular patch antenna, the return loss decreases, also the lowest frequency, on which antenna can work satisfactory, decreases.

\section{CONCLUSION}

The design of fractal (Probe Feed) antenna has been completed using IE3D software. The four fractal antennas are designed having same rectangular base geometry with different elliptical slots. The $S$ parameter displays of all four antennas are compared. The simulation results shows that as the elliptical slot dimension decreases on rectangular patch antenna, the performance of fractal patch antenna improves on the basis of three factors that are lowest frequency, multiband and $s_{11}$ values. Before going for fabrication we can optimize the parameters of antenna using a soft computing technique. Thus, use of fractal geometry results in a multi frequency and ultra-wide bandwidth operation of the antenna without employing any further modification. We can use fractal antenna for a multi band operation. 


\section{ACKNOWLEDGMENTS}

This research was supported by the Panjab University, Chandigarh, Guru Nanak Dev Engg. College, Ludhiana and SMDP Lab, Thapar University, Patiala, India. I am also thankful to Dr. Ravi Kumar, Assistant Professor, Department of Electronics and Communication Engineering, Thapar University and Mr. B.S Dhaliwal, Assistant Professor, Guru Nanak Dev Engg. College who devoted their valuable time and helped me in all possible ways towards successful completion of this work. I thank all those who have contributed directly or indirectly to this work.

\section{REFERENCES}

[1] Balanis C. A, "Antenna Theory: Analysis and Design”, John Wiley \& Sons, Inc, New York 1997.

[2] Breed Gary, "The Fundamentals of Patch Antenna Design and Performance", High Frequency Electronics Copyright (C) 2009 Summit Technical Media, LLC. March 2009.

[3] Singh Y.K, Ghosh S, Prathyush K, Ranjan Suyash, Suthram Sagar, Chakrabarty A, Sanyal S, "Design Of A Microstrip Patch Antenna Array Using le3d Software", Department of Electronics and Electrical Communication Engineering. Indian Institute of Technology, Kharagpur.

[4] Werner Douglas H, Haup Randy L. and WerneJ Pingjuan L, "Fractal Antenna Engineering: The Theory and Design of Fractal Antenna Arrays", IEEE Antennas and Propagation Magazine, Vol. 41, No. 5, October 1999.

[5] AbuTarboush H. F, Khan S., Nilavalan R, Al-Raweshidy H. S. and Budimir D., "Reconfigurable Wideband Patch Antenna for Cognitive Radio".

[6] Borja Carmen, "On the Behavior of Koch Island Fractal Boundary Microstrip Patch Antenna", IEEE Transactions on Antennas and Propagation, Vol. 51, No. 6, June 2003.

[7] Tariqul Islam Mohammad, Nazmus Shakib Mohammad, Misran Norbahiah, "High Gain Microstrip Patch Antenna" European Journal of Scientific Research ISSN 1450-216X Vol.32 No, pp.187-193, 2009.

[8] Chen Wen-Ling, Wang Guang-Ming, and Zhang Chen-Xin, "Small-Size Microstrip Patch Antennas Combining Koch and Sierpinski Fractal-Shapes", IEEE Antennas and Wireless Rropagation Letters, Vol. 7, 2008.

[9] Shanmuganantham T, Raghavan S, "Design of a compact broadband microstrip patch antenna with probe feeding for wireless applications", Int. J. Electron. Commun. (AEÜ) 63 653-659 (2009).

[10] Chavka G. G, "BEAUTY OF FRACTALS, DESIGN OF FRACTAL ANTENNAS", International Conference on Antenna Theory and Techniques, 17-21, Sevastopol, Ukraine pp. 76-81, September, 2007.

[11] Mohamed Ismail, sadek Hala El, Abdallahland Esmat A. Abdallahland Abd Elhady Amar, "Investigations on Novel Configurations of Triangular Fractal Microstrip Patch Antenna”, The 23rd National Radio Science Conference (NRSC 2006).

[12] Simulation of a $2.4 \mathrm{GHz}$ Patch Antenna using IE3D, Tutorial by Nader Behdad, EEL 6463, Spring 2007.
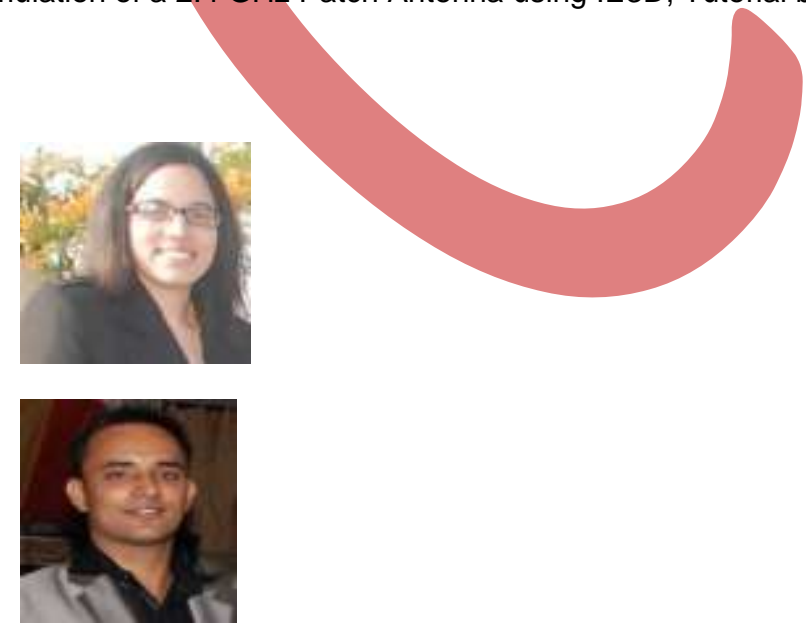

Monika Shukla She is born on Nov. $1^{\text {st }}, 1986$, did her B-Tech \& M-Tech from Guru Nanak Dev Engineering College, Ludhiana (Punjab)-India in Electronics and Communication Engineering in year 2010 \& 2012 respectively. Her major area of interest is antenna design and its applications. She has published three papers in the field of communication.

Somesh kumar $\mathrm{He}$ is born in 1988 at Sonipat-India. He received his Bachelor of Technology in 2009 in Electronics and Communication from C.D.M.E.G.E.C, Sirsa-India. He received his Master of Technology in 2012 in VLSI Design and CAD from Thapar University, Patiala-India. Currently, he is working as Assistant professor in Panjab University (PUSSGRC), Chandigarh. He has published seven technical and fundamental research papers in International Journals. 